\title{
Differential expression of autocrine motility factor re- ceptor (AMFR) mRNA in normal and cancer cells de- tected by in situ hybridization
}

\author{
HUANG BAiqu*, Avraham RAZ** \\ * Institute of Genetics and Cytology, Northeast Normal \\ University, Changchun 130024, China. \\ ** The Karmanos Cancer Institute, Department of Pathol- \\ ogy and Radiationn Oncology, Wayne State University \\ Medical School, Detroit, MI 48201, USA.
}

\section{ABSTRACT}

The receptor for autocrine motility factor (AMFR) is known to be involved in the process of AMF-mediated cell migration and metastasis. This paper describes the procedures of non-radioactive in situ hybridization (ISH) detection of AMFR mRNA in both paraffin-embedded surgical sections and cultured cells using either biotinylated oligonucleotide probes or digoxigenin-labeled RNA probes. The results showed that the AMFR mRNA was expressed at an enhanced level in hyperplastic and malignant tissues of breast and prostate cancer patient surgical specimens, indicating that the elevated AMFR expression was associated with the tissue malignancy. Moreover, AMFR mRNA was detected in both normal and carcinoma cells when cultured at a subconfluent density. However, AMFR expression was inhibited in confluent normal (3T3-A31 murine fibroblast and FHs738BL human bladder) cells while it continued to express in carcinoma (J82 human bladder) and metastatic (3T3-M murine fibroblast) cells irrespective of cell density. This suggested a cell-cell contact downregulation of AMFR mRNA expression in normal but not in cancer cells. The ISH data obtained in this study are closely consistent with the AMFR protein expression pattern previously reported, implying that the differential expression of AMFR gene may be regulated and controlled at the transcriptional level. 
In situ hybridization detection of AMFR mRNA

Key words: Autocrine motility factor receptor

(AMFR), non-radioactive in situ

hybridization, biotinylated probe,

digoxigenin-labeled RNA probe.

\section{INTRODUCTION}

Active cell locomotion and migration are fundamental to a variety of basic biological processes such as embryogenesis, morphogenesis, chemotactic, wound healing, invasion and metastasis[1]. It is known that regulation and direction of cell movement are affected by numerous components including growth factors and a group of cytokines[2,3]. A tumor-derived cytokine, the autocrine motility factor (AMF) was found to be able to induce and promote both directed and random cell migration [4]. In a series of studies aimed at unravelling the function and signalling pathway of AMF-stimulated motility, Raz and co-workers isolated a 78-kDa cell surface glycoprotein (gp78) from B16-F1 murine melanoma[5] and HT-1080 human fibrosarcoma[6] cell lines, and identified this protein as the receptor for autocrine motility factor (AMFR)[4]. The gene encoding the human AMFR was cloned from an HT-1080 fibrosarcoma cDNA library, and a polypeptide of 323 amino acids was deduced from the open reading frame of this $1.8 \mathrm{~kb} \mathrm{cDNA}$ clone[6]. The predicted protein had the structural features of an integral membrane protein, consisting of a 111 amino-acid extracellular domain, a hydrophobic 25 amino-acid transmembrane domain and a 187 amino-acid cytoplasmic region[6]. Previous work showed that a number of cellular and biochemical events were involved in the process of AMFAMFR interaction, including the activation of pertussis toxin-sensitive $\mathrm{G}$ protein[7], inositol phosphate production[8], stimulation of 12-1ipoxygenase[9], receptor phosphorylation[6] and ligand-receptor complex internalization[10]. Recently, it has been shown that the expression of AMFR (gp78) was down-regulated in normal cells by cell contact-inhibition, while in cancer cells it was constitutively expressed irrespective of cell density[1, 11, 12]. Moreover, enhanced expression of AMFR was found to be associated with bladder carcinomas, and this was accompanied by a concomitant decrease in the expression of E-cadherin, an intracellular adhesion molecule[13]. Therefore, the differential expression of AMFR may be a significant characteristic for identification of normal and carcinoma tissues and cells. A role for AMF and its receptor (AMFR) in metastasis and invasion was suggested based on their motilityregulating functions[14].

Because of the importance of AMF and AMFR in affecting cell motility and cell kinesis in metastasis, their signal transduction pathway, cellular localization and transportation, motility stimulating effects, as well as gene structure and expression were studied extensively (for reviews, see references [2] and [3]). However, the transcription and regulation of AMF and AMFR mRNAs at the cellular level in normal 
and tumor tissues have not been investigated up to this study.

In situ hybridization (ISH) permits the detection and localization of special mRNA sequences in cells and tissues, and has become a powerful technique in research and diagnosis. In this report, we describe the non-radioactive ISH studies on the expression of AMFR mRNA in sectioned tissues and in cultured cells of different sources, employing both biotinylated oligonucleotide and digoxigenin-labeld RNA probes complementary to human AMFR gene previously cloned[6]. The results indicated that the AMFR mRNA was expressed differentially in normal and tumor tissues, and this expression was regulated by cell density in normal but not in cancer cells. These ISH data closely correlate with the results obtained from immunofluorescence and Western blot analyses using anti-AMFR (anti-gp78) antibody[12].

\section{MATERIALS AND METHODS}

\section{Cells and culture conditions}

Normal (3T3-A31) and metastatic (3T3-M) murine fibroblast cells were cultured in Dulbecco's modified Eagle's medium (DMEM) containing 10\% bovine calf serum (BCS). The FHs738BL normal human bladder cells and J82 human bladder carcinoma cells were cultured in DMEM with $10 \%$ fetal bovine serum (FBS). All the media were supplemented with essential and non-essential amino acids, vitamins, L-glutamine, penicillin and streptomycin. Cultures were maintained at $37^{\circ} \mathrm{C}$ in an incubator with humidified atmosphere containing $5 \% \mathrm{CO}_{2}$.

\section{Surgical section specimens}

Paraffin sections of breast and prostate cancer tissues were prepared and supplied by the Department of Pathology, Harper Hospital, Detroit Medical Center, USA. Briefly, surgical tissue specimens from different patients were fixed in $4 \%$ paraformaldehyde in phosphate-buffered saline (PBS) for $4 \mathrm{~h}$ at $4^{\circ} \mathrm{C}$, dehydrated through graded ethanol and embedded in paraffin. Sections were cut at a thickness of 5-6 $\mu \mathrm{m}$ and mounted on microslides.

\section{Probe preparation}

For biotinylated probes, sense and antisense 21-base oligonucleotides complementary to the 5 ' portion of the coding region of human AMFR cDNA were designed and custom-synthesized. The sequence of the antisense probe was 5'-GTTCGTCCTTACGCTGCGACU- 3' (complementary to hAMFR mRNA) and the sense probe was 5'-GTCGCAGCGTAAGGACGAACU-3' (identical to hAMFR mRNA) where U-3' represents the Brigati tail[15], i.e., a 3'-end dUTP labeled with 6 biotin molecules. Besides, digoxigenin-labeled RNA probes were prepared by in vitro transcription using a Genius ${ }^{\mathrm{TM}}-4$ RNA labeling kit (Boeheringer Mannheim). In details, the $1.8 \mathrm{~kb}$ hAMFR cDNA was cloned into the pSPT18 transcription vector which contains the SP6 and T7 promoters adjacent to both sides of the polylinker. The recombinant vector was linearized with EcoRI or PvuII for production of antisense probe, and with HildIII or NheI for sense probe. A run-off in vitro transcription procedure was used to incorporate digoxigenin-11-UTP into RNA transcripts according to the manufacturer's instruction. The SP6 RNA polymerase was used to synthesize the antisense RNA probe from the EcoRI- or PvuII- linearized templates, whereas the sense RNA probe was synthesized by T7 RNA polymerase from the HildIII- or NheI-linearized templates. After the transcription reaction was completed, $2 \mu \mathrm{l}$ EDTA $(0.2 \mathrm{~mol} / \mathrm{L}, \mathrm{pH} 8.0)$ was added, and the RNA products were precipitated by adding $2.5 \mu \mathrm{l}$ lithium chloride (LiC1) and 2 volumes of chilled ethanol, and centrifuging at $12,000 \mathrm{~g}$ for $15 \mathrm{~min}$ at $4^{\circ} \mathrm{C}$. The RNA pellets were washed once with $70 \%$ ethanol, vacuum-dried and dissolved in diethylpyrocarbonate-treated water $\left(\mathrm{DEPC}-\mathrm{H}_{2} \mathrm{O}\right)$ and 


\section{In situ hybridization detection of AMFR mRNA}

stored at $-70^{\circ} \mathrm{C}$

\section{In situ hybridization (ISH)}

The ISH procedures were performed on a Microprobe System (Fisher Scientific) employing the capillary gap technology originally designed by Brigati[15].

\section{ISH with biotinylated oligonucleotide probes}

The slides with paraffin sections were dewaxed by immersing in Hemo-De (Fisher Scientific): xylene $=1: 3$ and then in xylene for 5 min each, and hydrated by passing through a decreasing ethanol series $\left(100 \%, 95 \%, 80 \%, 70 \%\right.$, and $\left.\mathrm{DEPC}-\mathrm{H}_{2} \mathrm{O}\right)$. The tissues were treated with an acetylation solution containing $1.2 \%$ triethanolamine and $0.25 \%$ acetic anhydride $(\mathrm{pH} 8.0)$ for $10 \mathrm{~min}$. After rinsed with Tris / Brij buffer ( $\mathrm{pH}$ 7.6) three times, tissues were incubated in pepsin solution (0.1-0.3 $\mathrm{mg} / \mathrm{ml}$ in $0.1 \mathrm{~N} \mathrm{HCl}$ ) for $5-10 \mathrm{~min}$ at $37^{\circ} \mathrm{C}$, and rinsed again. In some cases, the tissues were postfixed in $4 \%$ paraformaldehyde in PBS for $2-4 \mathrm{~min}$ at $4^{\circ} \mathrm{C}$, and rinsed twice with PBS. The hybridization was carried out at $52^{\circ} \mathrm{C}$ for $30-60 \mathrm{~min}$ in a solution containing $1-5 \mathrm{ng} / \mu \mathrm{l}$ biotinylated oligonucleotide probe in hybridization cocktail (Biomeda). The slides were washed at $52^{\circ} \mathrm{C}$ for 10-20 min with ProbeWash (Biomeda), rinsed with Tris/Brij and treated with a RNase solution containing $40 \mu \mathrm{M} / \mathrm{ml}$ RNase A and $2 \mu \mathrm{M} / \mathrm{ml}$ RNase $\mathrm{T}_{1}$ at $37^{\circ} \mathrm{C}$ for $30 \mathrm{~min}$. An UltraProbe ${ }^{\mathrm{TM}}$ basic kit (Biomeda) was used for the detection of ISH signals. Briefly, the hybridized specimens were incubated in avidin-alkaline phosphatase agent for $30 \mathrm{~min}$ at $40^{\circ} \mathrm{C}$, rinsed with Tris/Brij, and treated with Alkaline Phosphatase Enhancer (Biomeda) for $30 \mathrm{sec}$. The tissues were then incubated in 2 changes of freshly made chromagen solution, each for $30 \mathrm{~min}$ at $40 \sim \mathrm{C}$, and rinsed with Tris/Brij. The slides were finally counterstained with hematoxylin, rinsed, and mounted in Crystal Mount (Biomeda). For ISH of tissue culture specimens, slides seeded with cells grown to different extents of confluence were fixed in $4 \%$ paraformaldehyde at $4^{\circ} \mathrm{C}$ for $30 \mathrm{~min}$, washed 3 times with PBS, treated with $0.2 \mathrm{~N} \mathrm{HCl}$ for $20 \mathrm{~min}$ and washed again. The rest steps were the same as for sections except $1 \mu \mathrm{l} / \mathrm{ml}$ proteinase $\mathrm{K}$ was sometimes used instead of pepsin, and the hybridization temperature was $40^{\circ} \mathrm{C}$.

\section{ISH with digoxigenin-labeled RNA probes}

Tissue culture slides were fixed in $4 \%$ paraformaldehyde for $30 \mathrm{~min}$ at $4^{\circ} \mathrm{C}$ and washed twice in Tris/Brij. The cells were permeablized by treating with $1 \%$ Triton $\mathrm{X}-100$ solution (in $0.1 \mathrm{M}$ Tris-Cl, $\mathrm{pH}$ 7.5) for $10 \mathrm{~min}$ and rinsed. They were then treated with $0.2 \mathrm{~N} \mathrm{HCl}$ and acetylated with acetic anhydride as described above. The specimens were dehydrated in an graded ethanol series before prehybridized in a solution containing $50 \%$ formamide, $2 \times$ SSC, 1 x Denhardt's, $400 \mathrm{ug} / \mathrm{ml}$ tRNA and $250 \mu \mathrm{g} / \mathrm{ml}$ denatured salmon sperm $\mathrm{DNA}$ at $30^{\circ} \mathrm{C}$ for $1 \mathrm{~h}$ or longer. The cells were hybridized at $50^{\circ} \mathrm{C}$ for $4 \mathrm{~h}$ in the hybridization solution of the same composition with $20 \mathrm{ng} / \mu \mathrm{l}$ digoxigeninlabeled RNA probe added. The slides were washed 3 times with $2 \times$ SSC, $0.1 \%$ SDS, and treated with a RNase solution containing $40 \mu \mathrm{g} / \mathrm{ml}$ RNase A and $2 \mu \mathrm{g} / \mathrm{ml}$ RNase T1, at $37^{\circ} \mathrm{C}$ for $30 \mathrm{~min}$ to remove unhybridized RNA probes. The specimens were washed again and incubated in a $2 \mathrm{x}$ SSC solution containing $0.05 \%$ Triton X-100 and $2 \%$ normal sheep serum for $2 \mathrm{~h}$ before subjected to immunological detection. The immunodetection of ISH was carried out using the Genius ${ }^{\mathrm{TM}}$ 3 Nucleic Acid Detection Kit (Boehringer Mannheim) following manufacturer's instruction. In this procedure, hybridized probes were recognized by an alkaline phosphatase-conjugated antidigoxigenin antibody and then visualized with colorimetric substrates nitroblue tetrazolium (NBT) and 5-bromo-4-chloro-3-indolyl phosphate (x-phosphate).

All the steps in ISH were performed at room temperature unless otherwise specified. Solutions used in steps before hybridization were made with $\mathrm{DEPC}-\mathrm{H}_{2} \mathrm{O}$, and all the glasswares were also treated with DEPC- $\mathrm{H}_{2} \mathrm{O}$ and baked in an oven at $150^{\circ} \mathrm{C}$ overnight, to inhibit the activity of RNases. The processed slides were viewed under a light microscope and photographed on Kodak color (for biotinylated probes) or black-white (for digoxigenin probes) films. 


\section{RESULTS}

\section{ISH detection of AMFR mRNA in paraffin-embedded surgical specimens}

Paraformaldehyde-fixed and paraffin-embedded surgical specimens from breast cancer and prostate cancer patients were used for ISH to detect and compare the differential expression of AMFR mRNA in tissues of different malignancy. Fig 1 showed the sections of human breast cancer tissues after in situ hybridization with biotinylated oligonucleotide probes. Photographs marked A-D and a-d were pairs of sections of the same breast tissue specimens processed with sense (A-D) and antisense (a-d) AMFR probes, respectively. In this ISH procedure, the positive detection of AMFR mRNA by antisense probe was reflected by the purple-red color reaction in the cytoplasm while the sense probe was used as a negative control. All the specimens were counterstained with hematoxylin and the nuclei were visualized as blue color. Fig 1A and a were sections of highly differentiated breast tissues with a low degree of carcinogenicity. The tissues showed a minimal reactivity with both sense (A) and antisense (a) probes indicating that AMFR mRNA was expressed at an under-detectable level in these relatively normal tissues. In mammary glandular tissues with apparent hyperplasia, the expression of AMFR mRNA was significantly higher, as judged by the red-color positive staining (Fig lb). It is noted that the highly differentiated glandular tissues adjacent to the hyperplastic epithelial tissues in the same section showed a basically negative reaction to antisense probe (Fig lb, arrow). In Fig lc and d, malignant tumors of mammary glands were strongly hybridized to the antisense probe, and the cytoplasm of the tumor cells exhibited a prominent red color contrast to the surrounding interstitial tissues (Fig lc and d). All the tissues processed with the sense probe for a negative control demonstrated minimal hybridization signals (Fig 1A-D).

ISH of human prostate tissues gave a similar result. Fig 2A-D and a-d were sections hybridized with biotinylated sense and antisense probes, respectively. Tissues hybridized with sense probe resulted basically in a negative reaction (Fig 2A-D), whereas those with antisense probe exhibited differential staining intensity depending on the status of the tissues (Fig 2a-d). In details, low hyperplastic epithelial prostate tissues showed little staining (Fig 2a), and the hybridization signal was intensified with the increase of epithelium hyperplasia from papillary (Fig $2 b$ ) to highly hyperplastic (Fig 2c and d) tissues. In all the specimens, distinctive contrast in color reactivity between the glandular carcinoma tissues and the surrounding interstitial tissues was observed, suggesting that the ISH reaction for enhanced AMFR mRNA level in carcinoma cells was specific.

\section{ISH detection of AMFR mRNA in cultured cells}

This ISH experiment was designed to study the differential expression of AMFR mRNA in cells of different phenotypes cultured in vitro. Cells were allowed to grow 
In situ hybridization detection of AMFR mRNA
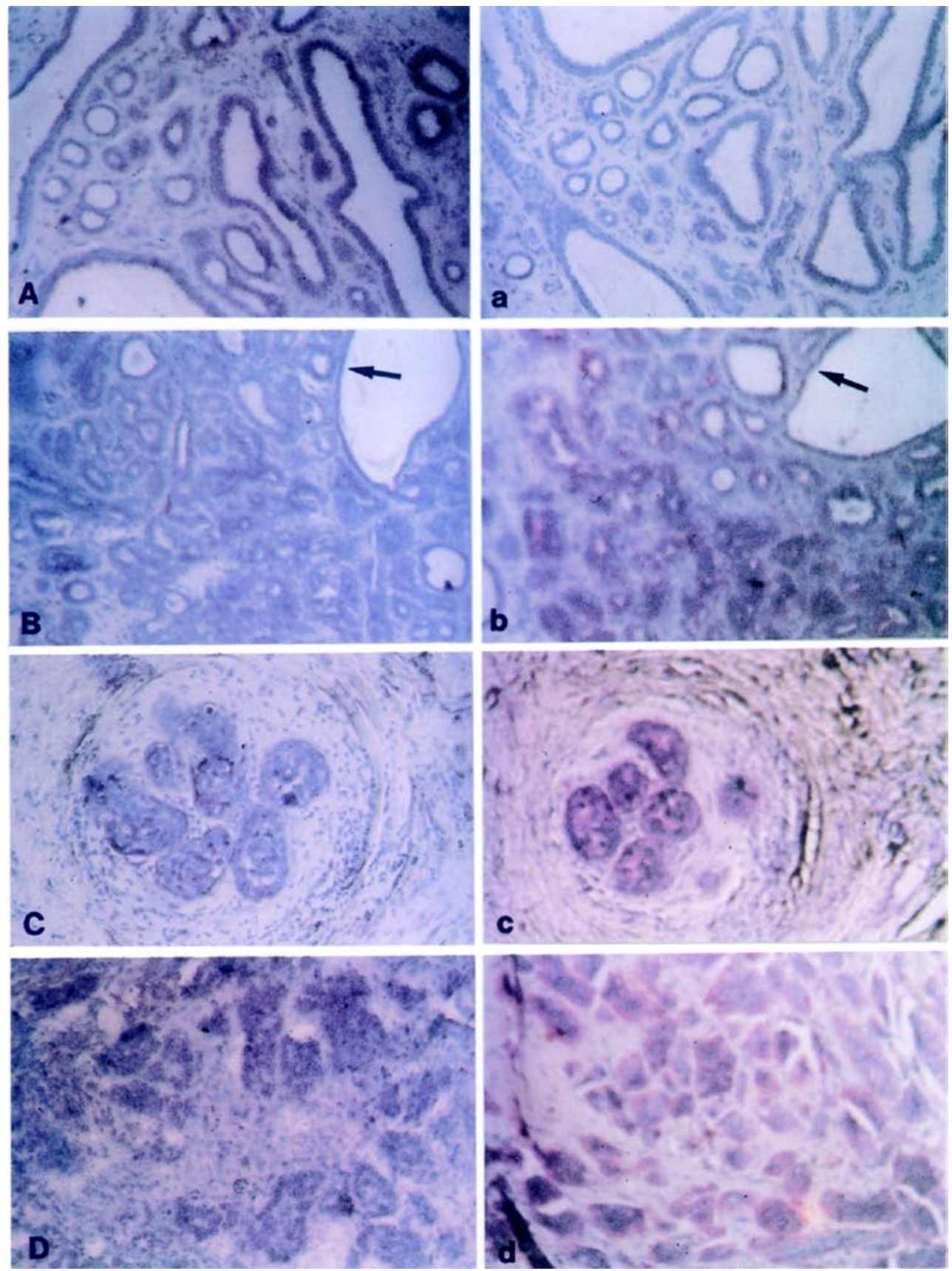

Fig 1. In situ hybridization of paraffin sections of human breast surgical specimens. The sections were hybridized with biotinylated oligonucleotide probes of AMFR gene, and counterstained with hematoxylin. A-D: ISH with sense probe for a negative control; a-d: ISH with antisense probe. A and a: normal breast tissue; B and b: hyperplastic glandular tissues; C, D and c, $\mathrm{d}$ : malignant tumors of mammary glands. The AMFR mRNA was undetectable in normal tissues (a) while an enhanced expression was seen in hyperplastic (b) and tumor (c, d) tissues as judged by the red color reaction in the cytoplasm. Note the differentiated glandular tissue in $b$ was negatively stained (arrow) contrast to the positively stained hyperplastic tissues adjacent to it. $\times 360$. 

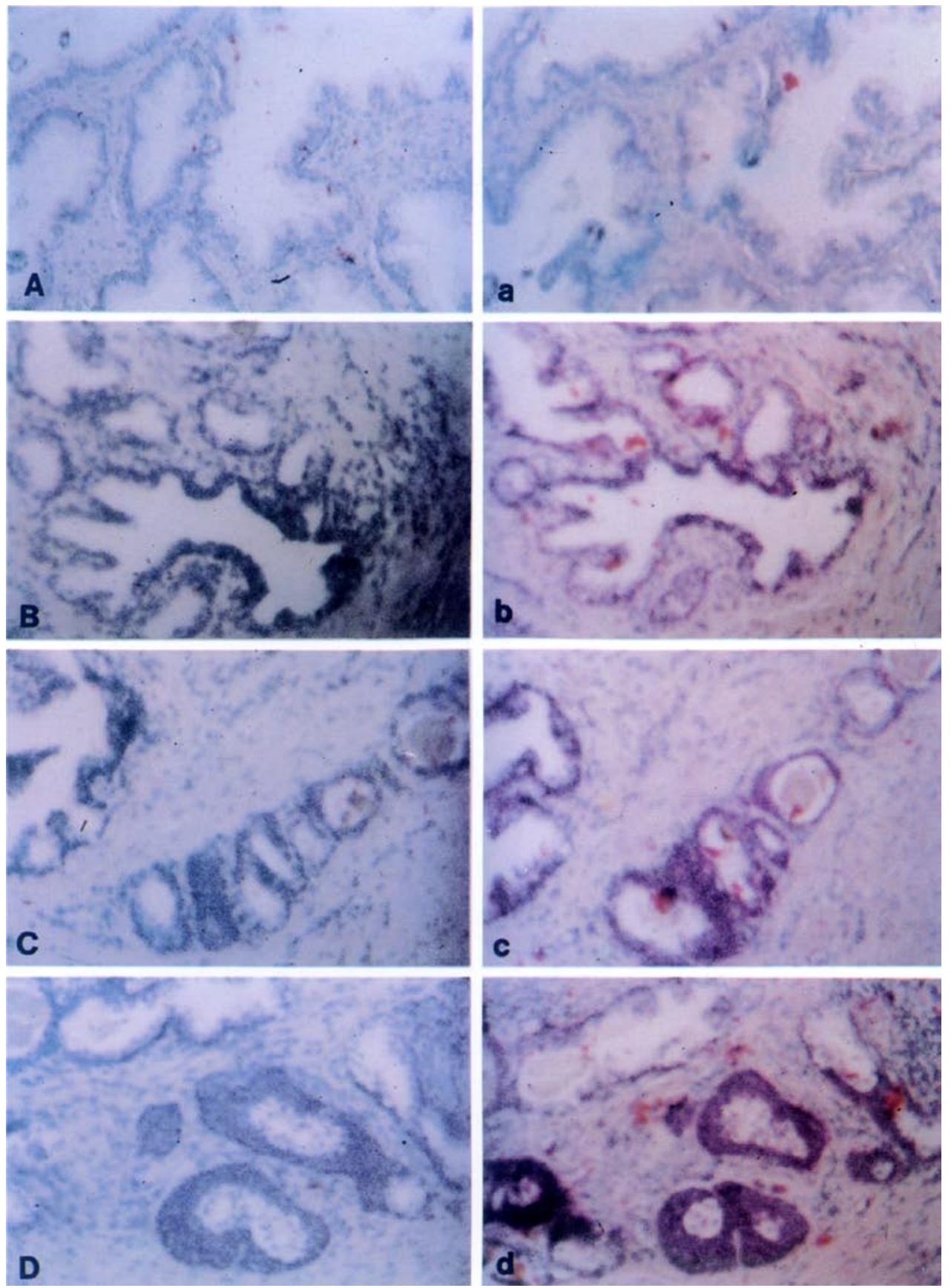

Fig 2. ISH of paraffin sections of human prostate surgical specimens processed in the same way as for those in Fig 1. A-D: ISH with biotinylated sense oligonucleotide probe; a-d: ISH with antisense probe. The highly differentiated prostate tissues showed little hybridization signal (a), whereas both papillary hyperplastic (b) and highly hyperplastic (c, d) tissues demonstrated a significantly higher expression of AMFR mRNA. $\times 360$. 
to different densities before being fixed and processed for ISH as described. Fig $3 \mathrm{~A}$ and a showed the ISH of FHs738BL human normal bladder cells cultured to a subconfluent (sparse) density in which no cell contact could be observed. A moderate expression of AMFR mRNA in sparse FHs738BL cells was detected by the biotinylated antisense oligonucleotide probe (Fig 3a), while the control ISH with sense probe resulted in a negative reaction (Fig 3A). However, when the cells grew to a confluent density, the AMFR mRNA became undetected in the cytoplasm (Fig $3 \mathrm{~B}$ and $\mathrm{b}$ ), suggesting that cell-cell contact of normal human bladder cells had an inhibitory effect on AMFR expression. In contrast, the J82 human carcinoma bladder cells expressed AMFR mRNA irrespective of the cell density, as both sparse (Fig 3c) and confluent (Fig 3d) cells exhibited positive ISH reaction.

Fig 4 depicted the ISH reaction of cultured murine fibroblast cells with digoxigeninlabeled sense (Fig 4A-D) and antisense (Fig 4a-d) RNA probes. The positive detection by antisense RNA probe was characterized by the dark blue to black color reaction in the cytoplasm (Fig 4a, c, d). A similar pattern of AMFR expression could be observed. Namely, the 3T3-A31 normal murine fibroblast cells expressed AMFR only when they were sparsely cultured with no cell contact (Fig 4a), while the expression was suppressed when cells were grown to confluent (Fig 4b). For 3T3M metastatic fibroblast cells, AMFR expression was detected at a similar intensity in both sparse (Fig 4c) and confluent (Fig 4d) density.

To conclude, the results presented in this report demonstrated that the AMFR mRNA was expressed differentially in normal and tumor tissues, i.e., an enhanced expression of the gene was associated with the malignancy of the tissues. Moreover, AMFR expression was down-regulated by cell-cell contact in normal cells but not in carcinoma or metastatic cells.

\section{DISCUSSION}

It is believed that the constitutive autocrine expression of AMF may confer metastatic capability on neoplastic cells[3], and AMF initiates cell motility by interacting with a cell surface receptor that is coupled to a pertussis toxin-sensitive $G$ protein[7, 16]. The receptor for AMF (AMFR), a $78 \mathrm{kDa}$ cell surface glycoprotein (gp78), has been characterized[4, 17], and the causal involvement of this protein in metastasis has been demonstrated both in vivo[17] and in vitro[4, 10]. Previous data suggested that regulation of AMFR expression could play a role in the control of stimulated cell locomotion, and the altered production of the gp78 receptor protein could endow tumor cells with motile and invasive capabilities[2]. For instance, it was shown that enhanced expression of gp78, accompanied by a concomitant decrease in E-cadherin expression, was correlated with higher grade disease, recurrence and incidence of metastasis in invasive and non-invasive clinical human bladder cancer specimens, as revealed by the immunofluorescence staining[13]. Moreover, Silletti et al.[12] investigated the regulation and pattern of AMFR protein expression in 
Huang BQ and A Raz
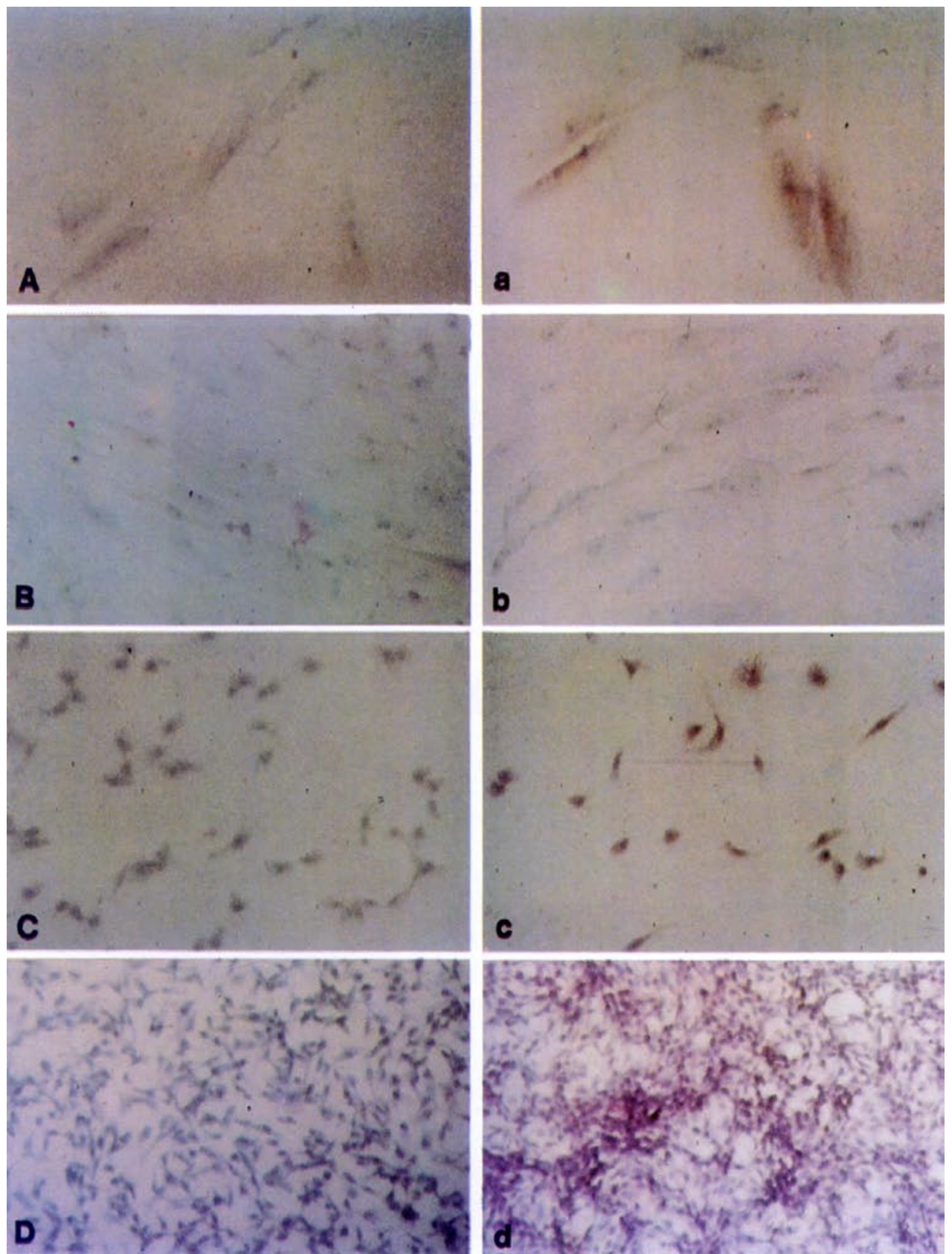

Fig 3. In situ hybridization of cultured cells with biotinylated AMFR oligonucleotide sense (A-D) and antisense (a-d) probes. A, a and B, b: FHs738BL human normal bladder cells; C, c and D, d: J82 human carcinoma bladder cells. AMFR mRNA expression was detected in sparsely cultured normal bladder cells (a) but not in confluent cells (b). In contrast, AMFR mRNA was expressed in both sparse (c) and confluent (d) carcinoma bladder cells. ISH with sense probe resulted in a negative staining (A-D). All the cells were counterstained with hematoxylin. $\times 400$. 
In situ hybridization detection of AMFR mRNA
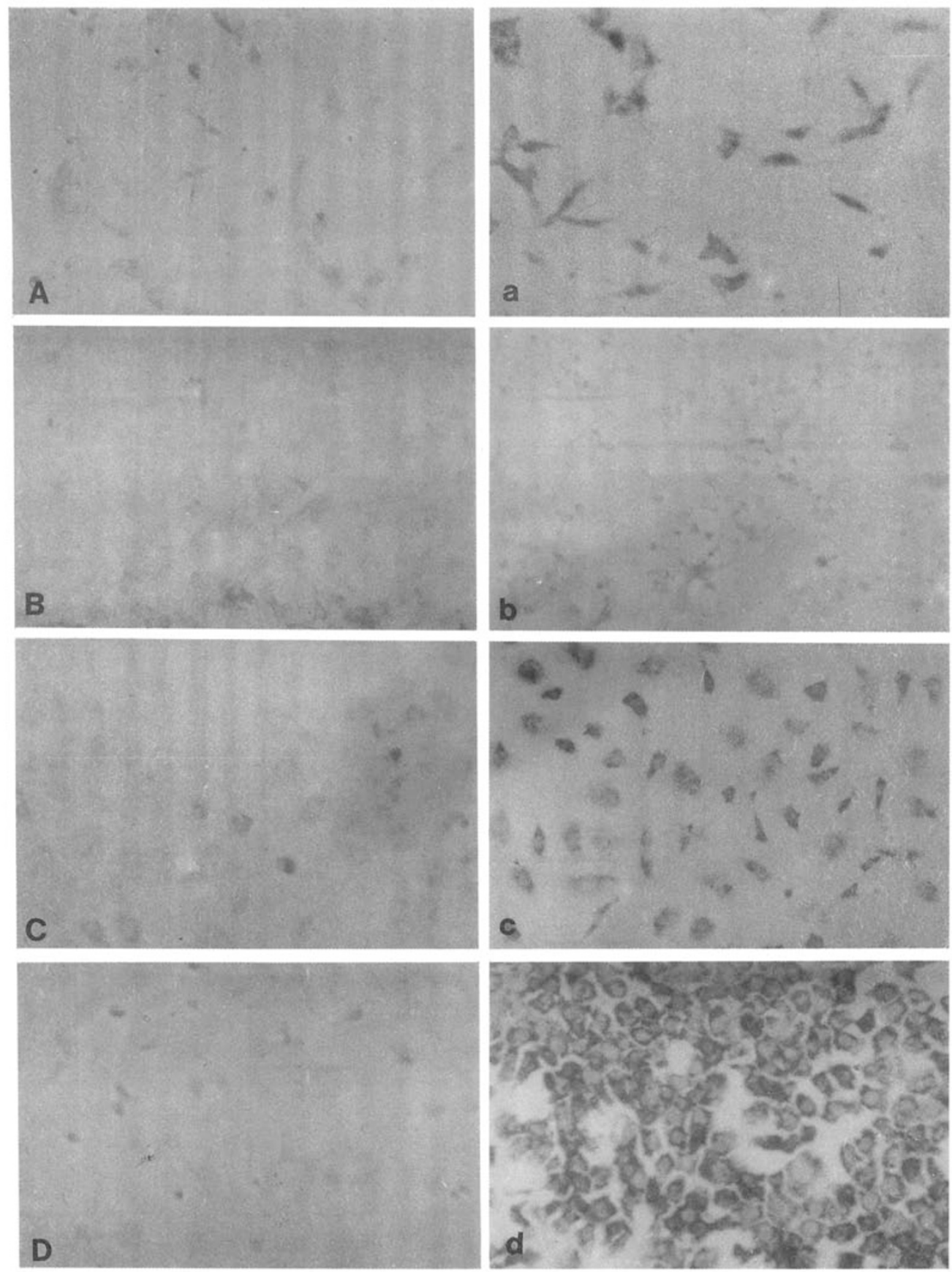

Fig 4. ISH of cultured murine fibroblast cells with digoxigenin-labeled sense (A-D) and antisense (a-d) RNA probes. A, a and B, b: 3T3-A31 normal fibroblast cells; C, c and D, d: 3T3-M metastatic fibroblast cells. In normal cells,only sparsely cultured cells reacted positively to antisense probe (a), while confluent cells gave a negative reaction (b). Both sparse (c) and confluent (d) metastatic cells hybridized to antisense probe to produce dark color signal in the cytoplasm. The ISH with sense probe resulted in a minimal reactivity $(\mathrm{A}-\mathrm{D}) . \times 400$. 
human bladder cells of different malignant phenotypes, i.e., the normal (FHs738BL), papilloma (RT4) and carcinoma (J82) cells. They found that all the three types of bladder cells expression the gp78 receptor protein at a similar level in subconfluent cultures though the distribution of the protein on cell surface differed among the cell types. In contrast, gp78 expression on the surface of FHs738BL normal cells was almost entirely abolished in response to cell-cell contact in confluent cultures. In RT4 papilloma cells, the expression of gp78 was restricted to the external edges of the peripheral cells of large colonies while those which contacted neighboring cells on all sides showed no surface staining. Meanwhile, the J82 carcinoma cells maintained a high level of surface gp78 expression even at a cell-cell contact density. Western blot analysis of total cellular gp78 protein content revealed the same expression pattern in these cell types[12]. All these data indicate that firstly the enhanced level of AMF receptor protein is associated with the malignancy of the cells or tissues, and secondly, cell-cell contact markedly down-regulates the expression of AMFR in the normal but not in the carcinoma cells.

The objective of this in situ hybridization study was to examine the pattern of AMFR gene expression at the transcriptional level, and to localize the AMFR mRNA at the cellular level in tissues and cells of different phenotypes. The ISH results obtained indicated that the AMFR mRNA was expressed in a similar manner to that of the expression of AMFR protein. In both breast (Fig 1) and prostate (Fig 2) cancer patient surgical specimens, the ISH signal for AMFR mRNA was significantly higher in the cytoplasm of malignant and hyperplastic tissues than in the differentiated, non-hyperplastic tissues, manifesting an elevated expression of AMFR mRNA in tumor tissues. Moreover, our ISH experiments with cell cultures showed that both normal and carcinoma cells expressed AMFR mRNA when they were cultured at a subconfluent density with no cell contacts (Fig 3a, c, Fig 4a, c). However, when the cells were grown to the confluence, the normal cells showed a minimal detection of AMFR mRNA (Fig 3b, Fig 4b), while carcinoma or metastatic cells continued to maintain a high level of expression (Fig $3 \mathrm{~d}$, Fig $4 \mathrm{~d}$ ). These ISH data are closely consistent with that of the AMFR protein expression detected by immunofluorescence techniques. Furthermore, previous experiments using quantitative Southern blot hybridization demonstrated that all the three different cell phenotypes (i.e., the normal FHs738BL, papilloma RT4 and carcinoma J82) had a roughly equivalent AMFR gene copy number and identical DNA restriction pattern[12]. In addition, a comparison of the complete nucleotide sequences between the AMFR gene from human HT-1080 fibrosarcoma and that from normal human placenta failed to detect any point mutations in the coding region of the gene (data not shown). These data suggested that gene structural difference or gene amplification may not be responsible for the observed differential expression of AMFR. Therefore, it seems reasonable to speculate that the characteristic differential expression of AMFR, i.e., the enhanced expression in tumor tissues and the cell-contact down-regulation in carcinoma cells, was controlled at the transcriptional level. 
In an attempt to understand the control and regulation of AMFR transcription, we cloned and sequenced a $0.7 \mathrm{~kb}$ upstream region of the gene, and identified a 39bp initiator (Inr) element which overlapped the transcription initiation site $(+1)$ and contributed the majority of AMFR promoter activity[18]. Furthermore, chloramphenicol acetyltransferase (CAT) reporter gene assay revealed a cell-density dependent pattern of promoter activity of this 39bp Inr element. Namely, confluent NIH-3T3 cells transfected with a CAT vector under the control of the $39 \mathrm{bp} \mathrm{Inr}$ expressed only $18.4 \%$ CAT activity of the sparse NIH-3T3 cells (100\%)[18]. This result provides evidence that the cell-contact down-regulation of AMFR expression in normal cells is controlled by the core promoter element in the upstream region of the gene. It is not known whether the differential expression of AMFR in normal and tumor tissue is also controlled by the same mechanism, though this is highly likely. Investigations to characterize in further details the promoter elements of the gene, as well as to identify the nuclear factors that interact with these elements are in progress.

The non-radioactive ISH procedures using biotinylated oligonucleotide probes or digoxigenin-labeled RNA probes employed in this study have certain advantages over the traditional methods using radio-labeled probes. The most prominent superiority of the non-radioactive ISH is the rapidness in producing results. For both probes used in this study, ISH procedures can be completed within 5-6 h instead of days even weeks of autoradiographic exposure for radioactive probes. This allows the repeated trials of experiments for optimization of ISH conditions to obtain the best results. Other advantages of non-radioactive ISH include the better histological resolution, good sensitivity, long shelf-life of labeled probes and non-hazardous handling of materials, etc.

An important parameter critical to the results of ISH is the proper fixation of specimens. The correct fixation for ISH should be so adjusted and balanced that it adequately retains the cellular mRNA, while the cytoplasm is not over crosslinked to allow the penetration of probes. There are reports to show that formalin-based fixatives give reasonably good results whereas ethanol/acetic acid-based precipating fixatives are insufficient for cellular RNA retention[19, 20]. In this study, 4\% paraformaldehyde in PBS was used for the fixation of both surgical tissue and cell culture specimens, and it resulted in positive ISH signals for AMFR mRNA in the cytoplasm, indicating that this fixation procedure was sufficient to retain the cellular mRNA. It was found that a brief treatment of sections and cells with a proteolytic enzyme (pepsin or proteinase $\mathrm{K}$ ) before hybridization was helpful for the penetration of probes and this gave rise to stronger ISH signals. In addition, for cell cultures, pretreatment of cells with a detergent (Triton X-100) to permeablize cell membrane was sometimes necessary, particularly when in vitro transcribed RNA probes were used, because these RNA probes were bigger in size than oligonucleotide probes and hence more difficult to penetrate the cell membrane. Although both biotinylated and digoxigenin-labled probes produced good ISH results, the former gave a better 
histological resolution after hematoxylin counterstaining, while it was difficult to counterstain the digoxigenin-stained specimens because of the close coloration between the ISH and hematoxylin signals. Therefore, the biotinylated probe procedure is more suitable for ISH of sectioned surgical tissues.

To conclude, the expression of AMFR mRNA may be useful as a marker for the malignancy and metastatic ability of cells and tissues. The non-radioactive ISH procedures described in this paper are sensitive enough to detect the differential expression of AMFR mRNA. This may be of predictive and diagnostic value in cancer clinic if more efficient, reproducible and quantitative ISH techniques are developed.

\section{ACKNOWLEGEMENTS}

This work was supported in part by a USPHS Grant CA51714 from the National Cancer Institute of USA to AR. AR is the recipient of the Paul Zuckerman Support Foundation for Cancer Research.

\section{REFERENCES}

[1] Silletti S, Raz A. Autocrine motility factor is a growth factor. Biochem Biophys Res Commun 1993; 194:446-57.

[2] Nabi IR, Watanabe H, Silletti S, Raz A. Tumor cell autocrine motility factor receptor. In: Goldberg ID. ed. Cell motility factors. Birkhauser Verlag Basel/Switzerland 1991; 163-77.

[3] Nabi IR, Watanabe H, Raz A. Autocrine motility factor and its receptor: Roles in cell locomotion and metastasis. Cancer and Metastasis Rev 1992; 11:5-20.

[4] Nabi IR, Watanabe H, Raz A. Identification of B16-F1 melanoma autocrine motility-like factor receptor. Cancer Res 1990; 50:409-14.

[5] Silletti S, Watanabe H, Hogan V, Nabi IR, Raz A. Purification of B16-F1 melanoma autocrine motility factor and its receptor. Cancer Res 1991; 51:3507-11.

[6] Watanabe H, Carmi P, Hogan V, Raz T, Silletti S, Nabi IR, Raz A. Purification of human tumor cell autocrine motility factor and molecular cloning of its receptor. J Biol Chem 1991; 266:3442-48.

[7] Stracke ML, Guirguis R, Liotta LA, Schiffmann E. Pertussis toxin inhibits stimulated motility independently of the adenylated cyclase pathway in human melanoma cells. Biochem Biophys Res Commun 1987: 64:339-45.

[8] Kohn EC, Liotta LA, Schiffmann E. Autocrine motility factor stimulates a three-fold increase in inositol phosphate in human melanoma cells. Biochem Biophys Res Commun 1990; 166:757-64.

[9] Timar J, Silletti S, Bazaz R, Raz A, Honn KV. Regulation of melanoma-cell motility by the lipoxygenase metabolite 12-(s)-HETE. Intl J Cancer 1993; 55:1003-10.

[10]Watanabe H, Nabi IR, Raz A. The relationship between motility factor receptor internalization and the lung colonization capacity of murine melanoma cells. Cancer Res 1991; 51:2699-705.

[11]Liotta LA, Mandler R, Murano G, Katz DA, Gordon RK, Chiang PK, Schiffmann E. Tumor cell autocrine motility factor. Proc Natl Acad Sci USA 1986; 83:3302-6.

[12] Silletti S, Yao J, Sanford J, Mohammed AN, Otto T, Wolman SR, Raz A. Autocrine motility factor receptor in human bladder carcinoma: Gene expression, loss of cell- contact regulation and chromosomal mapping. Intl J Oncol 1993; 3:801-7.

[13] Otto T, Birchmeier W, Schmidt U, Hinke A, Schipper J, Rubben H, Raz A. Inverse relation of E-cadherin and autocrine motility factor receptor expression as a prognostic factor in patients with bladder carcinoma. Cancer Res 1994; 54:3120-3. 


\section{In situ hybridization detection of AMFR mRNA}

[14]van Roy FV, Mareel M. Tumour invasion: effects of cell adhesion and motility. Trends Cell Biol 1992; 2:163-9.

[15] Park C-S, Manahan L J, Brigati DJ. Automated molecular pathology: one hour in situ DNA hybridization. J Histotechnol 1991; 14:219-29.

[16] Stracke ML, Kohn EC, Aznavoorian SA, Wilson LL, Salomon D, Krutzsch HC, Liotta LA, Schiffmann E. Insulin-like growth factor stimulates chemotaxis in human melanoma cells. Biochem Biophys Res Commun 1988; 153:1076 -83.

[17] Nabi IR, Raz A. Cell shape modulation alters glycosylation of a metastatic melanoma cell surface antigen. Intl J Cancer 1987; 40:396-401.

[18] Huang B, Xie Y, Raz A. Identification of an upstream region that controls the transcription of the human autocrine motility factor recepter. Biochem Biophy Res Commun 1995; 212:727-742.

[19] Singer RH, Lawrence JB, Villnave C. Optimization of in situ hybridization using isotopic and non-isotopic detection methods. Bio Techniques 1986; 4:230-50.

[20] Urieli-Shoval S, Meek RI, Hanson RH, Ferguson M, Gordon D, Benditt EP. Preservation of RNA for in situ hybridization: Carnoy's versus formaldehyde fixation. J Histochem Cytochem 1992; 40:1879-83.

Received 16-8-1995. Revised 16-10-1995. Accepted 24-10-1995 